\title{
Study of Deformations in a Large-Capacity Oil Storage Tank in the Presence of Subgrade Inhomogeneity Zones
}

\author{
Alexandr Tarasenko ${ }^{1}$, Petr Chepur ${ }^{1, *}$, and Alesya Gruchenkova ${ }^{1}$ \\ ${ }^{1}$ Industrial University of Tyumen, 625001 Volodarskogo str. 38, Tyumen, Russia
}

\begin{abstract}
Characteristics of a joint action of a subgrade and a large 50000 $\mathrm{m} 3$ capacity storage tank have been overviewed. The maximum allowable values of the RVSPK-50000 base immersion in the presence of the inhomogeneity zone have been determined given the stiffness of metal structures. To simulate the inhomogeneity zone we applied the DruckerPrager model - a linear elastoplastic material implemented in the finite element software package ANSYS. The dependences of the maximum design value of the outer tank bottom contour immersion on the inhomogeneity zone sector length have been obtained (in the range of 10 to 95 meters). It has been found that $95 \%$ of all cases of uneven immersion occurring in practice fall within this range according to data on diagnostics of 40 vertical steel tanks.
\end{abstract}

\section{Introduction}

Current trends in main oil transportation can be characterized by a constant increase in the unit of storage capacity in commercial storage tanks with subsequently remote regions with harsh engineering and geological construction conditions. Despite the fact that vertical steel tanks of more than 50,000 $\mathrm{m} 3$ capacity refer to I-class hazard structures and requirements for design decisions and quality of construction and installation works are at a very high level, there are cases of inhomogeneous immersion of RVSPK-50000 [1-6]. Research on the stress-strain state (SSS) of tanks during immersion is, as a rule, limited to strength analysis of the wall, bottom and annular plate structure. At the same time, simplified subgrade models are introduced that do not reflect the real nature of its deformation under the influence of operational and off-design loads. This approach ultimately leads to high errors in determining the SSS of the structure as a whole, and the lower circumferential joint in particular.

The authors propose to consider the joint work of the subgrade and the RVSPK-50000 tank as a thin-walled shell structure having finite bending stiffness. Based on the analysis results of diagnosing more than 40 RVSPK-50000 tanks [7-8], it has been shown that any outer bottom contour immersion can be represented as a combination of the wall surface arc value $\mathrm{L}$ along which the immersion develops and the immersion value $\mathrm{u}$. Let us assume that the base properties correspond to the design. Then, for the most unfavorable case of loading

*Corresponding author: chepur@me.com 
the tank metal structures in the immersion zone it is necessary to cut out a base sector and determine to what values the immersion can develop if the soil at the site of its development is completely absent. It is obvious that the value of immersion for the sector with a combination of operational loads is finite and will be determined by the elastic properties of the tank. Knowing the full range of immersion values encountered in practice and changing the value of the arc along which they occur, we can obtain the range of possible values of the outer tank bottom contour deformations. Immersion cannot exceed these values. The authors propose to use a research tool available in the ANSYS package [9-12] and replace the sector without the foundation base with the one with minimal strength properties, and perform the analysis of the interaction between the base and the structure using a model based on the Drucker-Prager strength criterion.

Introduction of powerful finite element analysis packages provided the opportunity to obtain reliable numerical solutions based on the actual geometry of the system and high detail of all interacting elements of the system.

In international practice there are cases of trouble-free operation of vertical steel tanks with uneven immersion of more than 1 meter; however, according to current design standards in the Russian Federation [21-22] the permissible uneven outer bottom contour immersion is limited to $40 \mathrm{~mm}$ for new vertical steel tanks and $80 \mathrm{~mm}$ for those being in service for more than 20 years. Permissible values of immersion in tank construction have significant differences from country to country, due to the type of construction materials used and design approaches in the regulatory documents (GOST, RD, SNiP, STO - Russia; API - the USA, EN - the European Union, British Standard - Great Britain).

In most cases, experts encounter the problem of immersion development when the reservoir has already been built and in operation for a long time. Considering that main oil transportation infrastructure is located in regions with harsh engineering and geological construction conditions designers are required to develop technological solutions for a particular project that would ensure normal lifetime operation conditions of the tank. An important condition for quality design is sufficient survey operations, the volume of which must be determined individually for each construction site depending on the characteristics of the structure and the construction properties of local soils. However, the amount of survey operations and the number of wells to be drilled are often designated incorrectly. Therefore, the customer's desire to maximize the reduction of costs (on survey operations) leads to an incorrect assessment of the geological conditions of the site. For example, according to regulatory documents, for a tank with the diameter of more than 60 meters and the design filling level of $17 \mathrm{~m}$ (base pressure under the central part of the bottom qbot = $144,2 \mathrm{kPa}$, under the foundation ring qbase $=203 \mathrm{kPa}$ ) only 5 wells are allowed to be drilled: one in the center and four along the contour at diametrically opposite points. This approach leads to the fact that design organizations apply design decisions based on incorrect information about the real properties of the soil forming the natural base. There are cases when there is no information about the presence of weak layers of organic soil in the base. Thus, errors at survey and design stages, violations of the construction and assembly operations technology, deviations in the hydraulic testing mode, changes of the oil transmission process scheme after the commissioning of the object (as a consequence, the emergence of off-design loads) may be the reasons for the emergence of inhomogeneity zones and uneven tank immersion.

The authors propose to apply the ANSYS finite element software package and analyze the RVSPK-50000 structure behavior features considering the joint operation of a reinforced concrete ring foundation, tank metal structures and a base with inhomogeneity zones composed of weak compressible soils. From [13-20] we can deduce that correct solution of such a problem requires a most accurate tank model to be developed that takes into account not only the stiffness of the structure, but also the contact interaction at the interface of the elements in the "soil-foundation-bottom-wall" system. When solving the 
contact problem it is important to consider the possibility of separation of the contact surfaces in immersion modeling, such as disconnection of the RVSPK metal structures from the foundation ring or foundation sagging over the inhomogeneity zone.

\section{Tank model development. Description of the design scheme}

A finite element model of RVSPK-50000 tank has been developed according to the design project of "CNIIPROEKTSTALKONSTRUKCIYA», with its verification reviewed in [17]. The tank diameter is $60.7 \mathrm{~m}$; height $-17.95 \mathrm{~m}$; wall thickness for belts I-XII ranges from 17 to $8 \mathrm{~mm}$ aligned with the inner surface; on wall belts V and VIII are located stiffening rings from roll-formed sections - 100x300 angles, $8 \mathrm{~mm}$ in thickness; the wind girder is an L-shaped structure of conjugated sheet and beam elements reinforced by braces located at $2.5 \mathrm{~m}$ intervals, welded to the XII wall belt via intermediate assembly plates; the foundation is circular, reinforced concrete, from rectangular section dimensioned $1.5 \mathrm{x} 0.4$ $\mathrm{m}$; the bottom 9 wall belts and annular plates are made from 16G2AF steel with a yield point $\sigma \mathrm{T}=440 \mathrm{MPa}$, other structures are from $09 \mathrm{G} 2 \mathrm{~S}$ steel with a guaranteed yield point $\sigma_{\mathrm{T}}$ $=325 \mathrm{MPa}$. To simulate the wall, bottom, annular plate and stiffening rings 4-node finite elements SHELL181 are used with six degrees of freedom per node, taking into account the membrane tension, compression and bending. For the foundation ring a 20 -node element SOLID186 is applied with three degrees of freedom per node. The subgrade is modeled using 10-node finite elements SOLID187 with three degrees of freedom per node and support of large deformations. When simulating immersion of the RVSPK-50000 foundation in a deformable soil volume the Drucker-Prager law was applied. In accordance with the Drucker-Prager strength criterion it is assumed that the yield surface does not change with the increase of plastic deformation; hence, there is no hardening effect, and the material is ideally elastoplastic. According to Drucker-Prager, the equivalent stress above which the material experiences plastic deformation is determined by taking into account the hydrostatic material squeeze reduction: the higher the mean stress, the greater the strength of the material. This condition is a modification of the Mises strength condition and better reflects the work of the base soils. The design scheme of RVSPK-50000 considering the acting load is given in Fig. 1.
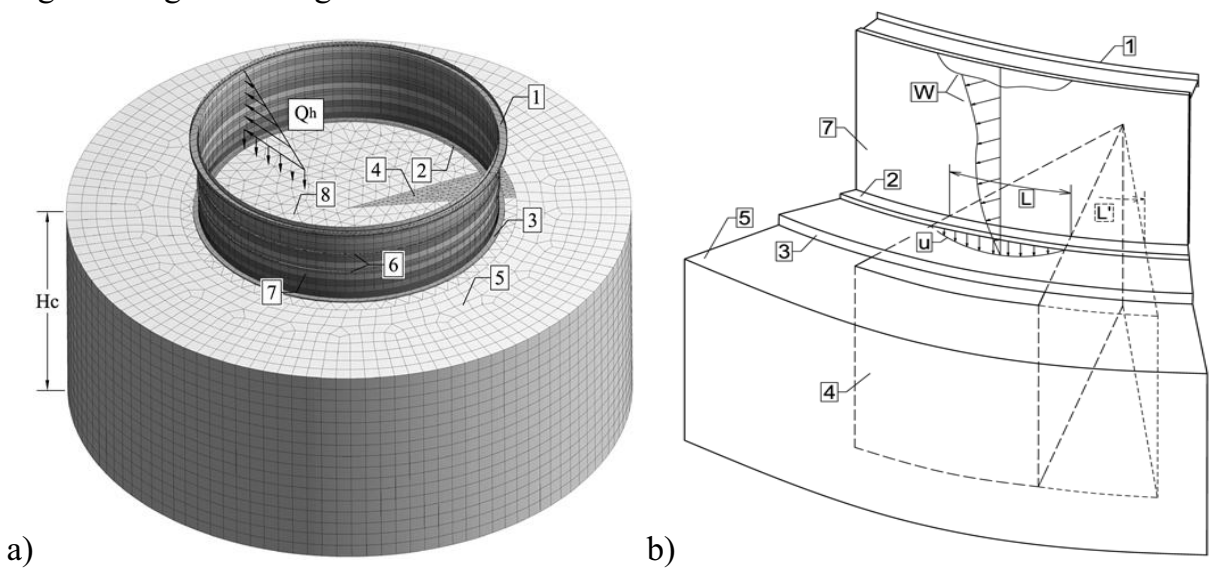

Fig. 1. Design scheme (a, b). 1 - wind girder; 2 - annular plate; 3 - reinforced concrete ring foundation; 4 - highly compressible soil of inhomogeneity zone; 5 - subgrade with design characteristics; 6 - stiffening ring on wall belts V and VIII; 7 -RVSPK-50000 wall; 8 - central bottom section; $\mathrm{Qh}$ - hydrostatic load; $\mathrm{R}$ - tank radius; $\mathrm{L}$ - inhomogeneity zone sector length (along the outer contour of the bottom); Hc - compressed thickness; W - wall radial movements; $\mathrm{u}$ - bottom outer contour immersion. 
Previous diagnostic tests [8] confirm that the inhomogeneity zone under the VST bottom and annular plate tends to form a triangular sector. The inhomogeneity zone in this research is given as a triangular sector with the arc size L along the VST outer contour. This design scheme was proposed for the first time by I.V. Slepnev [13], where the design loading was produced by cutting a segment of the VST foundation ring. However, in [11] a section of the wall, annular plate and bottom "sagged" above the inhomogeneity zone, i.e. soil and foundation within the specified sector limits were non-existent. This was justified by the fact that such a loading scheme reflects the most unfavorable operating conditions of VST metal structures in the presence of the inhomogeneity zone.

When performing test calculations, as well as the analysis of [12] and diagnostic survey data [8], intervals that determine the minimum and maximum values of the inhomogeneity zone sector of the RVSPK-50000 base were set (along the outer contour of the bottom). The minimum value was $\mathrm{L}_{\min }=10$ meter, maximum $-\mathrm{L}_{\max }=95.3$ meters (which corresponds to the RVSPK-50000 roll). The authors set the properties of a highly compressible soil in the inhomogeneity zone using the Drucker-Prager model, taking into account the most unfavorable case ever encountered according to diagnostic tests of real tanks. Table 1 shows the physical and mechanical characteristics of the soil for the modeled base sections.

Table 1. Basic physical and mechanical characteristics of soils for the modeled base sections.

\begin{tabular}{|c|c|c|c|}
\hline Characteristics & Unit & $\begin{array}{c}\text { Weak high-plasticity clay soil of } \\
\text { the inhomogeneity zone (4 - fig. 1) }\end{array}$ & $\begin{array}{c}\text { Artificially compacted sand } \\
\text { and clay soil (5 - fig. 1) }\end{array}$ \\
\hline Elastic modulus, $\mathrm{E}$ & $\mathrm{MPa}$ & 5 & 30 \\
\hline Poisson's ratio, $\mu$ & - & 0.43 & 0.3 \\
\hline Density, $\rho$ & $\mathrm{kg} / \mathrm{m} 3$ & 1800 & 1650 \\
\hline Cohesion, $\mathrm{c}$ & $\mathrm{kPa}$ & 0 & 4 \\
\hline $\begin{array}{c}\text { Angle of internal } \\
\text { friction, } \varphi\end{array}$ & degree & 14 & 36 \\
\hline
\end{tabular}

The thickness of the model's active base zone is taken to be $H_{c}=40 \mathrm{~m}$. This value was determined in accordance with the recommendations [21] based on the calculation results of the foundation plate on the elastic base for a highly compressible soil in the inhomogeneity zone (4). The area of the active base zone is taken to be $11304 \mathrm{~m}^{2}$ and its diameter is $120 \mathrm{~m}$.

The boundary conditions of the model are defined by a rigidly fixed lower edge of the subgrade at the level of "-40 m", as well as by the exclusion of the lateral displacement of soil along the perimeter of the computational domain. A nontrivial problem of model development is consideration of contact interaction between loaded structures. So, contacts of the bottom metal structures, wall and annular plate (surface-surface, edge-surface) connected by welds are modeled as deformable bonded, but without the possibility of separation - command «bonded». However, contact of the bottom, annular plate and foundation with the subgrade, the annular plate with the foundation ring cannot be set to «bonded», because for large deformations in the base inhomogeneity zone the contact area may change: there can be disconnection of metal structures from foundations, raising and lowering of the foundation ring and the bottom, whereby both interpenetration of contact surfaces (the reinforced concrete foundation into the soil) and their separation at any point is possible. So, the authors used an algorithm, the augmented Lagrange method, which takes into account the sliding friction force proportional to the normal reaction in the contact model. In this case, the contact area can be changed and includes both areas of adhesion, sliding and complete separation. This technique allows controlling the amount of introduction of the contact surfaces, also, the contact stiffness values in the normal direction based on the Young's modulus - E and the size of adjacent elements are calculated. The calculation results confirm the validity of applying the approach used. Thus, at great values 


\section{TPACEE-2016}

of the inhomogeneity zone the circumferential joint of RVSPK-50000 is actually "hanging" over the highly compressible soil base section. The model consists of 301647 finite elements and takes into account the physical and geometric nonlinearities.

\section{Results}

Fig. 2-3 show the subgrade deformations diagrams and RVSPK-50000 metal structures with a minimum considered inhomogeneity zone $\mathrm{L}=10 \mathrm{~m}$ and maximum $-\mathrm{L}=95.3 \mathrm{~m}$ (along the outer contour of the bottom), in which case there is tank roll with a break at the interface of the weak soil and soil with design characteristics. The RVSPK-50000 design model with the inhomogeneity zone considers hydrostatic load $\mathrm{Q}_{\mathrm{h}}=144.2 \mathrm{kPa}$, oil innage height $\mathrm{H}_{\text {взл }}=17 \mathrm{~m}$ (oil density $\rho=865 \mathrm{~kg} / \mathrm{m}^{3}$ ). For visualization purposes, on the diagram soil and metal structures deformations are presented using a scale factor $\mathrm{x} 3$.

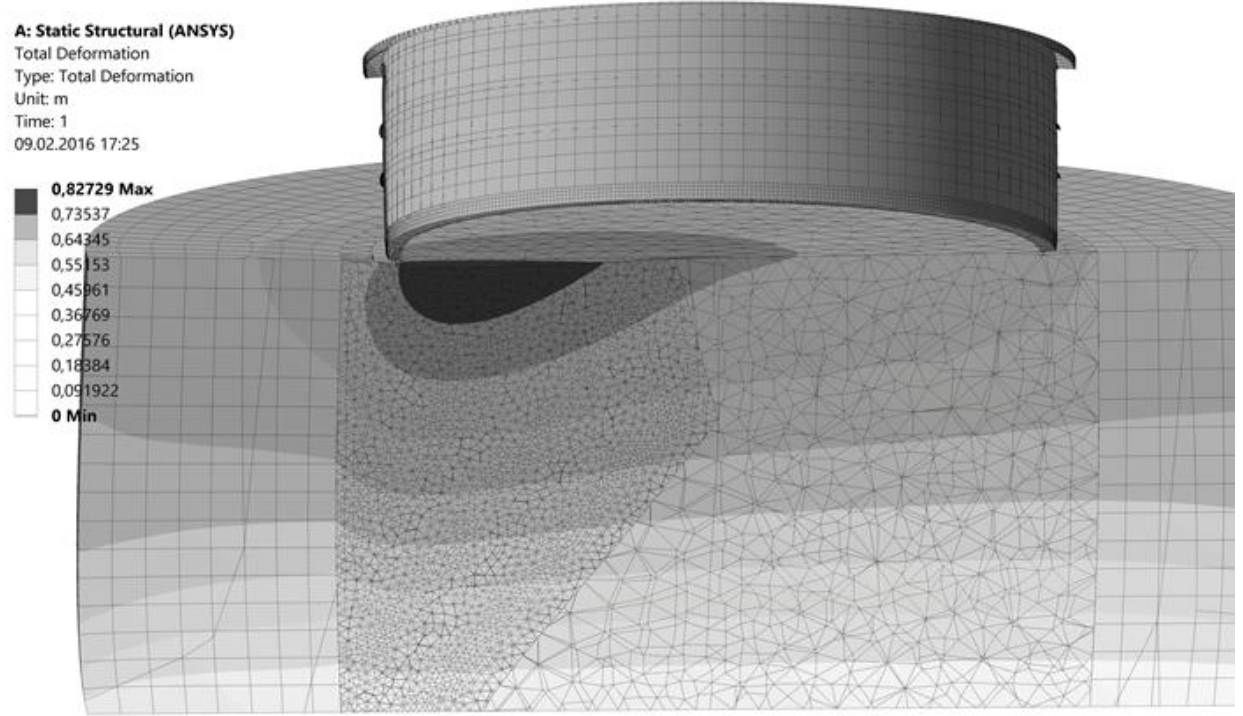

Fig. 2. Diagram of RVSPK-50000 movements with the inhomogeneity zone $\mathrm{L}=10 \mathrm{~m}$ (section view).

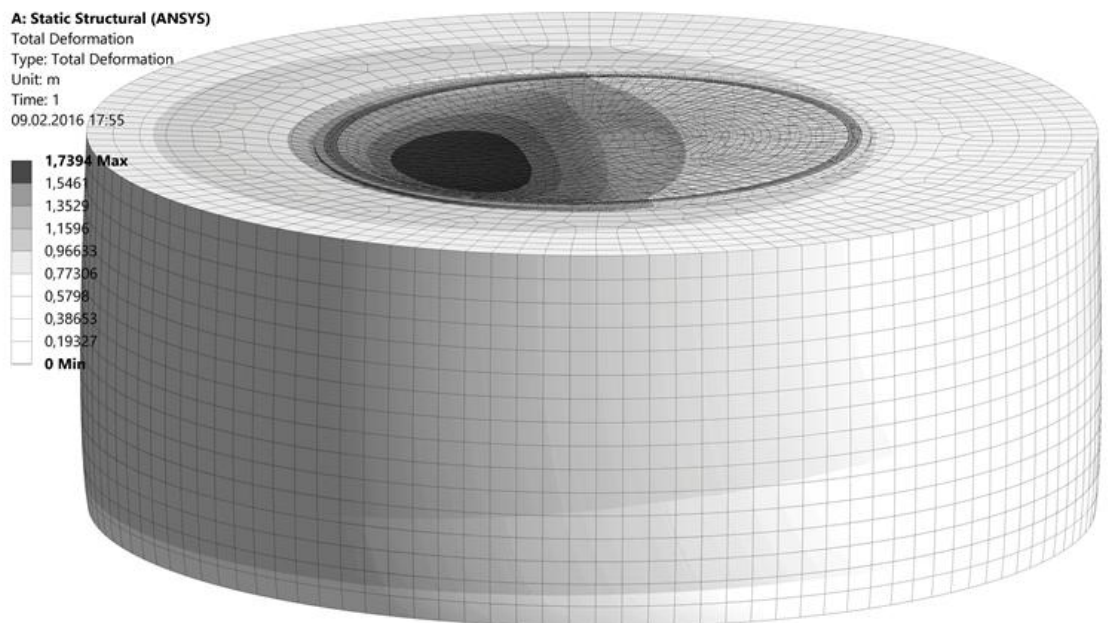

Fig. 3. Diagram of RVSPK-50000 base and foundation movements with the inhomogeneity zone $\mathrm{L}=$ $95.3 \mathrm{~m}$ (tank removed for clarity). 


\section{TPACEE-2016}

The authors conducted interpretation of the data obtained from finite element modeling and found that when the tank is filled to the maximum the bottom outer contour immersion above the inhomogeneity zone with the length $\mathrm{L}=95 \mathrm{~m}$ (1/2 of the RVSPK-50000 perimeter) can reach $325 \mathrm{~mm}$. For the inhomogeneous immersion zone with the sector length $\mathrm{L}=10 \mathrm{~m}$ the immersion of the bottom outer contour is $29 \mathrm{~mm}$. The greatest values of the bottom outer contour immersion are observed in the middle of the inhomogeneity zone regardless of the sector length. A graph has been built (Fig. 4) that shows the dependence of the maximum design value of the RVSPK-50000 bottom outer contour immersion on the inhomogeneity zone sector length.

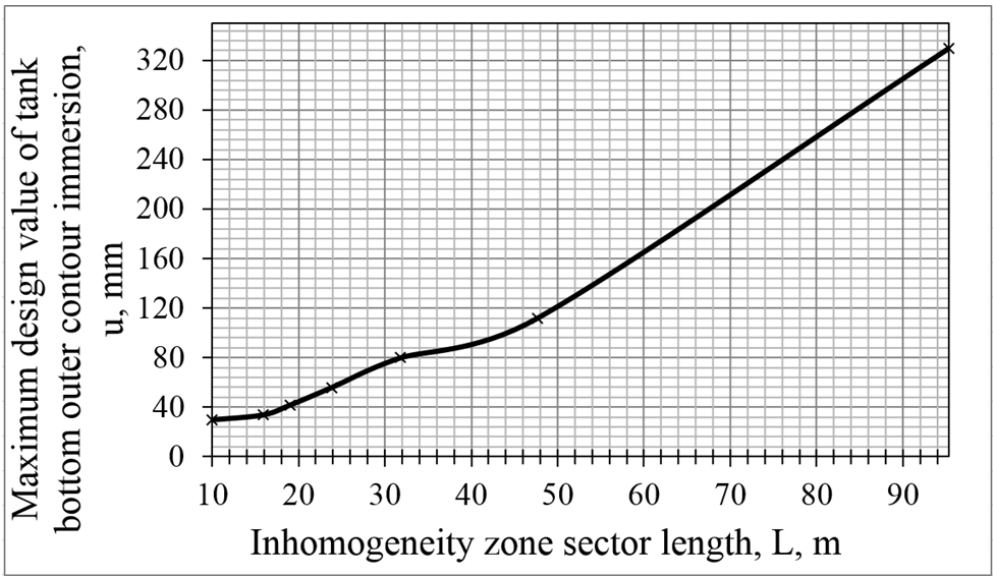

Fig. 4. Dependence of the maximum design value of the RVSPK-50000 bottom outer contour immersion on the inhomogeneity zone sector length.

Note that structures of this type have a large cylindrical stiffness that prevents the development of uneven immersion. However, it should be considered that if the bottom outer contour immersion is more than $40 \mathrm{~mm}$ when the inhomogeneity zone sector length is $20 \mathrm{~m}$ there occurs an increased stress-strain state in metal tank structures, which confirms the requirements of the regulatory documents.

The developed model considering the contact interaction of the base with the structure has allowed establishing the acting stresses in the tank metal structures and identifying worst case deformations in the presence of inhomogeneous immersion [22-23]. At the inhomogeneity zone sector length of 30-50 meters the maximum stresses in all load-bearing elements of RVSPK-50000 exceed the yield point of steel. However, at maximum values of the inhomogeneity zone sector $(\mathrm{L}=70-95.3 \mathrm{~m})$ the level of SSS decreases. This is due to the stiffness characteristics of the structure and forms of possible deformations under nonaxisymmetric loads. Note that the greatest stresses occur in the three areas: the wind girder above the inhomogeneity area, in places of wall break at the interface of two subgrade types, as well as in the additional stiffening ring on the $\mathrm{V}$ wall belt.

Dependences of the acting equivalent stresses in the RVSPK-50000 metal structures on the inhomogeneity zone sector length for the metal structures of the I-XII wall belts, stiffening rings on the V and VIII belts, as well as the wind girder are given in Fig. 5. 


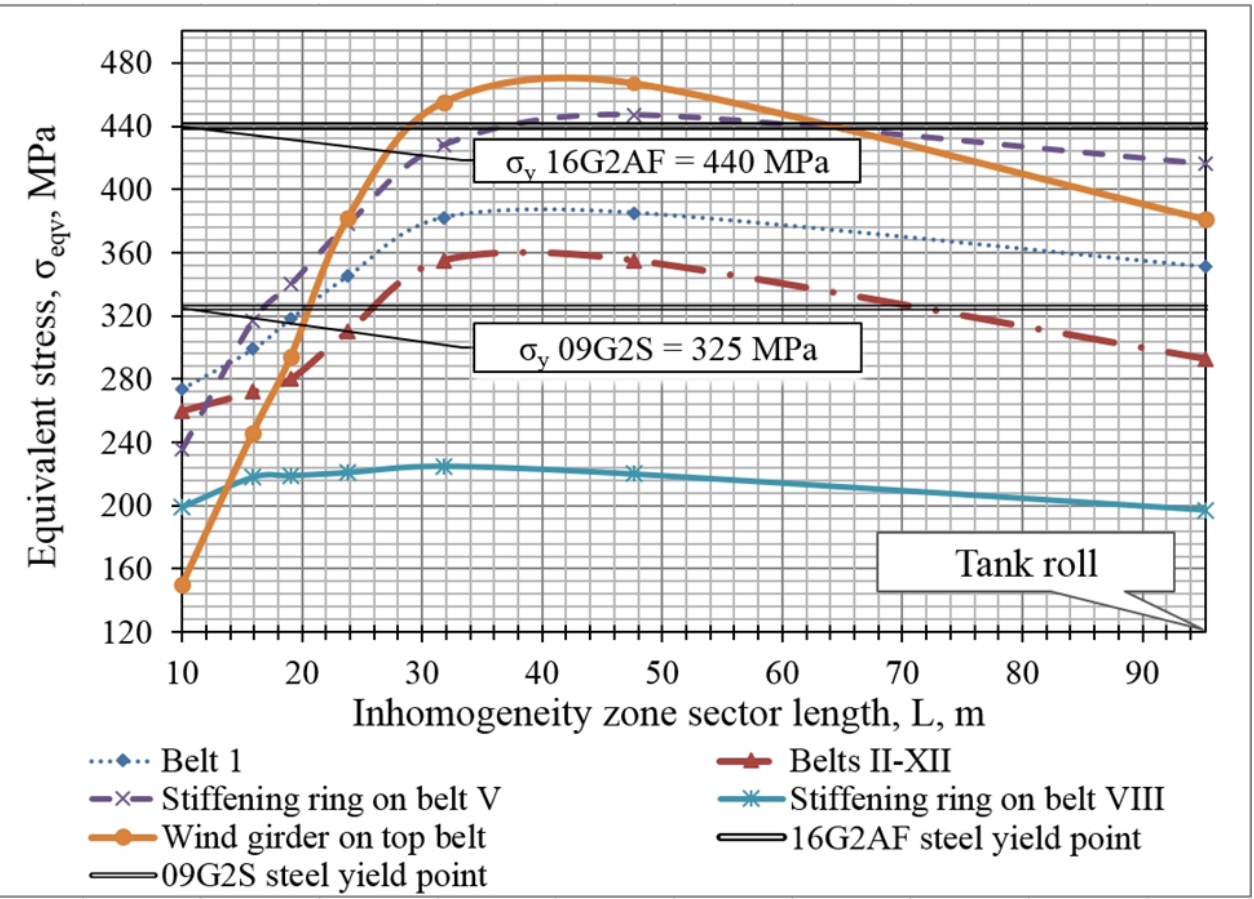

Fig. 5. Dependences of the acting equivalent stresses in the RVSPK- 50000 metal structures on the inhomogeneity zone sector length.

\section{Conclusions}

1. A finite element model of RVSPK-50000 has been developed that allows us to determine the stress-strain state of the structure and soil mass in presence of the inhomogeneity zone taking into account the physical Drucker-Prager model, contact interaction of the "base-foundation-bottom-tank" system.

2. It has been established that if there is inhomogeneous immersion, separation of the reinforced steel ring from the annular plate and bottom results in a sharp increase in the stress-strain state of the entire structure. This highlights the need to develop and improve solutions to enhance the design of the foundation ring.

3. The dependences of the maximum design value of the outer tank bottom contour immersion on the inhomogeneity zone sector length have been obtained (in the range of 10 to 95 meters). It has been found that $95 \%$ of all cases of inhomogeneous immersion occurring in practice fall within this range according to data on diagnostics of 40 vertical steel tanks.

\section{References}

1. G.G. Vasilyev, A.A. Salnikov, Neftyanoe khozyaystvo, Oil Industry, 2, 106-108 (2015)

2. V.B. Galeev, Stress-strain state of tanks built on weak waterlogged soils, DSc. Thesis (Tyumen, 1987)

3. A.A. Tarasenko, A.A. Gruchenkova, P.V. Chepur, Pipeline transport: Theory and Practice, 53, 32-37 (2016)

4. V.A. Ilyichev, R.A. Mangushev, Geotechnics reference. Bases, foundations and underground structures (Publishing house ASV, Moscow, 2014) 
5. A.A. Tarasenko, P.V. Chepur, Fundamental research, 12-1, 67-84 (2014)

6. A.S. Gorelov, Inhomogeneous ground base and their influence on the operation of vertical steel tanks: monograph (Nedra, SPb, 2009)

7. P.A. Konovalov, R.A. Mangushev. S.N. Sotnikov, A.A. Zemlyanskiy, A.A. Tarasenko, Foundations of steel tanks and deformations of their bases (Publishing house Associacii stroitel'nyh vuzov, Moscow, 2009)

8. A.A. Tarasenko, M.V. Sayapin, Oil and Gas, 1, 52-56 (1999)

9. G.G. Vasilyev, A.A. Tarasenko, P.V. Chepur, Y. Guan, Neftyanoe khozyaystvo, Oil Industry, 10, 120-123 (2015)

10. A.A. Tarasenko, P.V. Chepur, D.A. Tarasenko, Neftyanoe khozyaystvo, Oil Industry, 4, 88-91 (2015)

11. A.A. Tarasenko, P.V. Chepur, S.V. Chirkov, Neftyanoe khozyaystvo, Oil Industry, 10, 121-123 (2014)

12. A.A. Tarasenko, P.V. Chepur, S.V. Chirkov, Neftyanoe khozyaystvo, Oil Industry, 3, 123-125 (2016)

13. I.V. Slepnev, Stress-strain elastic-plastic state of steel vertical cylindrical tanks with irregular immersion of bases (MISI, Moscow, 2014)

14. A.A. Tarasenko, P.V. Chepur, A.A. Gruchenkova, Fundamental research, 12-7, 1418 1422 (2014)

15. P.V. Chepur, Stress-strain state of the tank in the development of irregular immersion of its foundation: thesis for the Candidate of technical sciences degree (Gubkin Russian State Oil and Gas University, Moscow, 2015)

16. P.V. Chepur, A.A. Tarasenko, Fundamental research, 2-8, 1671-1675 (2015)

17. P.V. Chepur, A.A. Tarasenko, Fundamental research, 7-1, 95-100 (2015)

18. P.V. Chepur, A.A. Tarasenko, Fundamental research, 12-1, 97-102 (2015)

19. P.V. Chepur, A.A. Tarasenko, A.A. Gruchenkova, Fundamental research, 12-3, 514519 (2014)

20. S.V. Chirkov, A.A. Tarasenko, P.V. Chepur, Oil and Gas, 5, 72-78 (2014)

21. A.A. Tarasenko, P.V. Chepur, Y. Guan, Neftyanoe khozyaystvo, Oil Industry, 4, 134$136(2016)$

22. GOST R 52910-2008. Vertical cylindrical steel storage tanks for oil and petroleum products (Standartinform, Moscow, 2007)

23. RD-23.020.00-KTN-283-09. Rules of repair and reconstruction of oil storage tanks 1000-50000 cubic meters in capacity (2009) 